\title{
Initial Studies of Mating Disruption of the Tomato Moth, Tuta absoluta (Lepidoptera: Gelechiidae) Using Synthetic Sex Pheromone
}

\author{
Miguel Michereff Filho ${ }^{a}$, Evaldo F. Vilela ${ }^{a}$, Gulab N. Jham ${ }^{b}$,

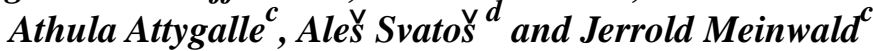 \\ ${ }^{a}$ Departamento de Biologia Animal, Universidade Federal de Viçosa, 36571-000 Viçosa - MG, Brazil. \\ ${ }^{b}$ Departamento de Química, Universidade Federal de Viçosa, 36571-000 Viçosa - MG, Brazil. \\ ${ }^{c}$ Baker Laboratory, Department of Chemistry, Cornell University, Ithaca, NY 14853, U.S.A. \\ ${ }^{d}$ Institute of Organic Chemistry and Biochemistry, Academy of Sciences of the Czech Republic, \\ Flemingovo nám. 2, 16610 Prague 6, Czech Republic.
}

Running head: Mating disruption of Tuta absoluta using sex pheromone

\begin{abstract}
O potencial do componente principal sintético do feromônio sexual de T. absoluta (Meyrick) para a interrupção dos acasalamentos foi estudado em parcelas (0,01 hectares) cultivadas com tomate estaqueado. Os efeitos de doses do $3 E, 8 Z, 11 Z$-14:Ac (0 a $80 \mathrm{~g}$ i.a./ha) aplicadas nas parcelas foram determinados considerando a orientação dos machos às armadilhas contendo feromônio sexual, os acasalamentos em gaiolas e os danos no tomateiro. Os mais altos níveis de interrupção na orientação dos machos (60-90\%) foram obtidos com 35 a $50 \mathrm{~g} / \mathrm{ha}$ de feromônio sexual. Nenhum tratamento com feromônio foi hábil para reduzir significativamente a percentagem de folíolos minados e de frutos broqueados ou a freqüência de acasalamentos em relação às parcelas não-tratadas. A falha na técnica de interrupção dos acasalamentos pode ser atribuída à composição do feromônio sintético e às doses usadas, à alta densidade populacional da praga e à imigração de fêmeas acasaladas para dentro da área tratada.
\end{abstract}

The potential of the synthetic major component of T. absoluta (Meyrick) sex pheromone for mating disruption was studied in small plots ( 0.01 hectares) with fresh-market tomato crop. The effects of the application of the sex pheromone $3 E, 8 Z, 11 Z-14$ :Ac (from 0 to $80 \mathrm{~g}$ a.i./ha) were assessed on male orientation to pheromone baited traps, mating in cages and plant damage. The highest levels of interruption in male orientation (60-90\%) were found in plots treated with 35 to 50 $\mathrm{g} /$ ha of sex pheromone. However, no treatment with pheromone was capable of significantly reducing the percentage of mined leaflets or bored fruits or the frequency of mating in cages compared to the control plots. The failure in mating disruption technique may be attributed to the composition of the synthetic pheromone, doses used, high pest population density, and mated female migration to the area treated.

Keywords: sex pheromone, mating disruption, Tuta absoluta, Scrobipalpuloides absoluta, Gelechiidae, tomato

\section{Introduction}

The tomato moth, Tuta absoluta (=Scrobipalpuloides absoluta) (Meyrick), is widely distributed in South America, and has been the most devastating tomato pest in Brazil since it was found in $1980^{1-3}$. This pest occurs during all stages of the fresh-market and processing tomatoes, and larvae can cause losses up to $100 \%$, due to attacks to leaves, flowers, stems and especially fruits ${ }^{2}$.

*e-mail: mch@alunos.ufv.br
Chemical control is the only method available, but the limited efficacy of insecticides against $T$. absoluta larvae forcing Brazilian growers to adopt heavy insecticide applications, sometimes 36 sprayings per season ${ }^{4}$. This is totally undesirable not only for the environmental and food contamination, but also because it increases the cost of production and reduces natural enemies of the pest ${ }^{5,6}$.

Sex pheromones have been used to control several insect pests on different crops by the mating disruption technique, including gelechiids such as Keiferia lycopersicella 
(Walsingham) in tomatoes ${ }^{7}$, Pectinophora gossypiella (Saunders) in cotton ${ }^{8}$, and Anarsia lineatella (Zeller) in peaches ${ }^{9}$. It may also be used to control T. absoluta. The major sex pheromone component was identified as (3E,8Z,11Z)-3,8,11-tetradecatrien-1-yl acetate [hereafter called $3 E, 8 Z, 11 Z-14: A c]^{10}$, and field evaluations showed that $100 \mu \mathrm{g}$ of $3 E, 8 Z, 11 Z-14$ :Ac impregnated in rubber septa was more attractive to males than virgin females caged in traps ${ }^{11}$. In addition to the major component, a minor constituent $(<10 \%$ of volatile material) was identified as (3E,8Z)-3,8-tetradecadien-1-yl acetate [3E,8Z$14: A c]^{12,13}$. Although the $90: 10$ binary blend of synthetics $3 E, 8 Z, 11 Z-14$ :Ac and 3E,8Z-14:Ac has been very attractive to males in laboratory biossays, the major component itself has been effective in field tests ${ }^{14}$, and presently it has been used for monitoring purposes. Field studies of other moth pests have shown that disruption of pheromone communication is also achieved in some cases by the major pheromone component ${ }^{15}$. Based on this information, we were encouraged to carry out the first mating disruption trial for the tomato moth.

We made the first attempt to disrupt the orientation of T. absoluta males to pheromone-baited traps, using the synthetic major component of its sex pheromone, (3E,8Z,11Z-14:Ac), leading to pest mating disruption and, consequently reduction of tomato plant damage. The results should be used to assess the potential of mating disruption in the control of the pest in fresh-market tomato.

\section{Experimental}

This study was carried out between August and December 1996 on six hectares of commercial fresh-market tomatoes in Turvolândia, Minas Gerais State, Brazil. Tomato seedlings (Santa Clara III cultivar) were transplanted on August 19 and trellised on bamboo stakes on September 14. Adjacent tomato fields were $300 \mathrm{~m}$ away to the North and South.

After transplanting, fifteen small plots $13 \times 18 \mathrm{~m}(0.02$ ha) were set up within the tomato cultivation area, approximately $70 \mathrm{~m}$ away from each other. The same insecticide program was established for the treatment and control plots and consisted of (1) standard insecticide sprayings - two weekly applications from transplanting to the week prior to the first synthetic sex pheromone application, alternating cartap (180 g a.i./ha), abamectin (300 ml a.i./ha), chlofluazuron (25 ml a.i./ha), lambdacyalothrin (70 $\mathrm{ml}$ a.i./ha) and methyl paration (180 $\mathrm{ml}$ a.i./ha), recommended for leafminer, fruit borer and tomato vector virus control ${ }^{16}$. The insecticides were mixed with mineral oil ( $1.500 \mathrm{ml} / \mathrm{ha}$ ) and applied using a knapsack sprayer fitted with a cone nozzle and rated at 300 l/ha. (2) during the first week of pheromone application (4 weeks after transplanting) cartap was used in two sprayings, to reduce the T. absoluta caterpillar population. (3) In the second week of pheromone application ( 9 weeks after transplanting) deltamethrin (30 $\mathrm{ml}$ a.i./ha) was aerial sprayed, using a tractor-mounted sprayer, and rated at 100 l/ha, besides the two weekly sprayings with the same active ingredient used in the standard insecticide sprayings.

\section{Pheromone synthesis}

The synthetic major component of the T. absoluta sex pheromone $(3 E, 8 Z, 11 Z)-3,8,11$-tetradecatrien-1-yl acetate $^{10,11}$ was used as the chemical disruptant. This compound was synthesized at the Baker Laboratory (Department of Chemistry, Cornell University, USA). In order to obtain sufficient quantity of the $3 E, 8 Z, 11 Z-14$ :Ac (1) for bioassays, the synthetic scheme described previously by us ${ }^{11}$ was used. This synthesis which is summarized is Scheme 1, started from protected pentynol $\mathbf{2}$, which was converted to an acetylenic Grignard reagent by heating with ethylmagnesium bromide. This Grignard reagent was used to carry out a $\mathrm{Cu}(\mathrm{I})$ catalyzed nucleophilic displacement on the tosylate of 2pentyn-1-ol (3), giving diyene 4 in quantitative yield. Twofold hydroboration of $\mathbf{4}$ was accomplished using dicyclohexylborane, formed from the borane-methyl sulfide complex and cyclohexene. After hydrolysis of the resulting alkadienyldiborane with acetic acid, followed by careful oxidation of the residual borane species with $\mathrm{H}_{2} \mathrm{O}_{2}$, a mixture of the deprotected (4Z,7Z)-4,7-decadien-1-ol and its THP protected derivative 5 (1:1) was isolated. Fortunately, this mixture could be conveniently converted directly to bromide 6 by treating with triphenylphosphine dibromide. The bromide 6 was coupled with the lithium salt of 1(tetrahydropyran-2-yloxy)-3-butyne in a mixture of THF/ DMPU at $0^{\circ} \mathrm{C}$ to give compound 7. Deprotection of 7 to alcohol $\mathbf{8}$ could be accomplished efficiently by stirring with ion-exchange resin (Dowex 50WX8) in methanol. Alcohol 8 was reduced with $\mathrm{LiAlH}_{4}$ in dry diglyme at $120-140^{\circ} \mathrm{C}$ for 2$5 \mathrm{~h}$. Heating at higher temperatures and/or longer reaction times affords a product contaminated with over-reduced material and isomerized polyenols (GC-MS analyses). Finally, the alcohol $\mathbf{9}$ was acetylated to the desired compound $\mathbf{1}$ in 95\% purity (GC analyses on SE-54 and Carbowax capillary columns). The mass spectrum of synthetic 1 and that of the major component of the T. absoluta sex pheromone, obtained using an ion-trap detector under identical conditions, were indistinguishable from each other. In addition, gas chromatographic retention times of both compounds were the same. 


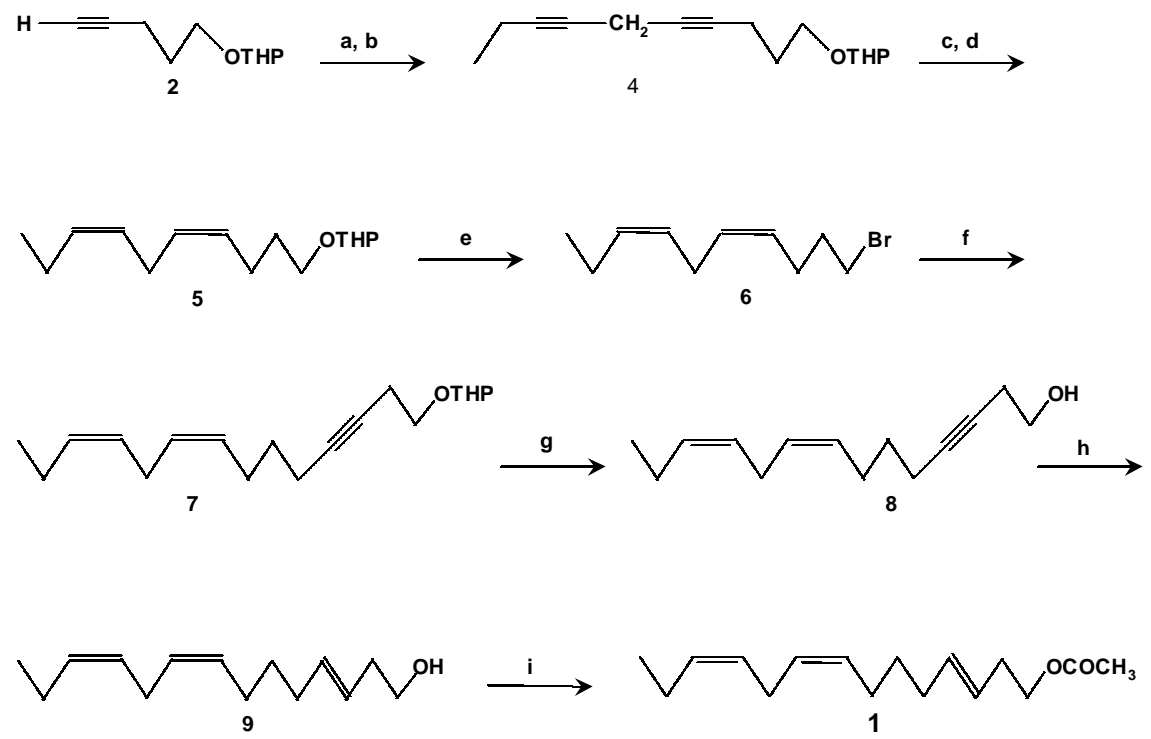

Scheme 1. Pheromone synthesis: (a) EtMgBr/THF; (b) $\mathrm{CH}_{3}-\mathrm{CH}_{2}-\mathrm{C} \equiv \mathrm{C}-\mathrm{CH}_{2}-\mathrm{OTs}$ (3) / $\mathrm{Cu}$ (I) $\mathrm{Br}-\mathrm{Me}_{2} \mathrm{~S},-20^{\circ} \mathrm{C}-0^{\circ} \mathrm{C}$; (c) $\mathrm{Cy}_{2} \mathrm{BH}(4.4$ equiv); (d) $\mathrm{CH}_{3} \mathrm{CO}_{2} \mathrm{H}$; (e) $\mathrm{PPh}_{3} / \mathrm{Br}_{2}$ (1.5 equiv), $\mathrm{CH}_{2} \mathrm{Cl}_{2}$; (f) $\mathrm{Li}=\overbrace{-\mathrm{OTHP}}$, DMPU/THF $0^{\circ} \mathrm{C}$; (g) Dowex/MeOH; (h) LiAlH 4 /diglyme, $120-140^{\circ} \mathrm{C}$; (i) $\mathrm{Ac}_{2} \mathrm{O} /$ pyridine.

\section{Field experiment}

Disruption dispensers for pheromone liberation were made from rubber septa (red, 15 x 8 mm, Sigma Company, California, USA), which had been previously extracted with dichloromethane ${ }^{11}$. Solutions of $3 E, 8 Z, 11 Z-14$ :Ac were prepared in double-distilled hexane (Merck, p.a. quality). Appropriate volumes of the solutions were pipetted into the rubber septa to provide doses of 4, 8, 16 and $32 \mathrm{mg}$ a.i./ dispenser, respectively. After solvent evaporation (6 hours), the dispensers were transferred to plastic seal-top bags and kept at $-10^{\circ} \mathrm{C}$ until placement in the field.

Twenty-five dispensers were placed in each plot $(2,500$ points/ha) using 5 x 5 grids with a $3 \mathrm{~m}$ spacing within the row and $2 \mathrm{~m}$ between the rows. The dispensers were attached by hand on bamboo stakes or directly on the trellis string with a small piece of wire. The dispenser height corresponded to the level of the top of the tomato foliage. The dispensers were substituted at 4 week intervals.

Mating disruption of T. absoluta was performed in two steps. At the first application, the synthetic sex pheromone was placed in the field after trellising of the plants to stakes (4 weeks after transplanting) and assessed from September 17 to October 22. Doses of 0,100, 200 and $400 \mathrm{mg}$ a.i./plot were tested, corresponding to the control (D1) where no pheromone was applied, $10 \mathrm{~g}$ a.i./ha (D2), $20 \mathrm{~g}$ a.i./ha (D3) and $40 \mathrm{~g}$ a.i./ha (D4), respectively. At the second application (9 weeks after transplanting) the experiments were carried out from October 23 to December 10 and doses D1, D2, D3, D4, including D5, which was a $800 \mathrm{mg}$ a.i./plot dose ( $80 \mathrm{~g}$ a.i./ha) were assessed. The synthetic sex pheromone was always applied after 12.00 $\mathrm{h}$. The treatments were repeated three times in a completely randomized block design. Each block contained five small plots, defined by stakes. The blocks were oriented crosswise in the direction of the prevailing wind to minimize the interference among the different plots.

Indirect monitoring methods were used to assess pheromone application efficiency in $T$. absoluta mating disruption, such as reduction of trap catches, number of cages with successful mating, and levels of leaf and fruit damage in the pheromone-treated and control plots. Due to the extent of T. absoluta damage to fruit production, all the assessments were associated within two phenologic stages in the tomato plant: the vegetative stage (vegetative growth until the first flowers) and reproductive stage (after the first fruits in at least $50 \%$ of the plants).

\section{Synthetic-baited pheromone traps}

The intensity of interruption in the feral males was assessed weekly, from 0 to 35 days after each pheromone application. A round trap ${ }^{11}$ containing a red rubber septa (15 x $8 \mathrm{~mm}$, Sigma company, USA) impregnated with $100 \mu \mathrm{g}$ of $3 E, 8 Z, 11 Z-14$ :Ac was used in each plot. The trap was installed in the middle of the plot and among the three innner rows, at a height corresponding to the median third part of the plant canopy. The traps were checked daily, and the insects were discarded after $12.00 \mathrm{~h}$ according to UchoaFernandes et al. ${ }^{17}$ and each trap was filled with water and drops of neutral detergent on the bottom plant to capture the moths. Pheromone lures were substituted every 3 weeks. 
The trap catches in the control plots, found from the trellising of the plants to stakes until the final fruit harvest, were used as indicators of the moth population in the field. Data were expressed as males caught per trap per day, on a weekly time scale.

\section{Mating station}

Mating incidence was found using mating tables placed in the treated and control plots. Two assessments were conducted between the insecticide sprayings, on August 26 and October 30 (always one week after each pheromone application). The mating tables consisted of wooden cages $(30 \times 15 \times 15 \mathrm{~cm})$ with galvanized wire netting $(0.5 \mathrm{~mm}$ mesh $)$ on the sides. Ten mating cages were placed randomly inside each plot, on the two inner rows, and the height installation corresponding to the median third part of the plant canopies. Two pairs of virgin moths (1-3 days old) were placed inside each cage at $15.00 \mathrm{~h}$. The assessment was made the next morning, after the mating period of the species $(5.00 \text { to } 11.00 \mathrm{~h})^{17}$. The females were removed and taken to the laboratory, where the three last abdominal segments of each moth were cut and squashed on glass slides with orceine acetic stain. Mating was confirmed by the presence of spermatozoid bundles with blue coloring in the squashed material. The percentage of cages with mating was calculated for each plot and assessment time. The moths used in the cages came from a colony bred in field cages, which was started with insects obtained locally.

\section{Foliage and fruit damage assessment}

Twenty tomato plants were inspected in each plot to check the damage caused by $T$. absoluta. Fifteen plants were randomly sampled from the four inner rows of each plot. Foliage injury by the larvae was assessed weekly, from 0 to 28 days after each pheromone application. The mean percentage of mined leaflets on each chosen plant was found by observing the leaflets with yellow mines $(0.1-0.5 \mathrm{~cm}$ long) on the first three completely opened leaves from the plant apex (modified from Gravena ${ }^{18}$ ). Fruit damage was assessed every two weeks, from 0 to 42 days after the second pheromone application, between October 23 and December 10. The percentage of damaged fruits was found at each date by inspecting three clusters of fruits per plant (240 fruits per plot) which contained unripe fruit approximately $4 \mathrm{~cm}$ crosswise diameter (modified from Gravena ${ }^{18}$ ). This procedure allowed new fruit clusters to be inspected which were formed on the plant at each assessment.

\section{Statistical analyses}

Pheromone trap catches were transformed in $\log _{10}(\mathrm{Y}+1)$ and the percentages of mined leaflets and damaged fruits were transformed using arcsine square root $(\% / 100)$, respectively, before being analyzed. Data from pheromone treated and control plots were submitted to multiple regression analysis, for which models were obtained by selecting significant variables by backward stepwise procedure using the Statistica software (StaSoft, Tulsa, UK). The pheromone dose (X1) and the time after pheromone application (X2) were used as independent variables, while the trap captures and mined leaflets and damaged fruit were the dependent variables (Y). Independent analyses were conducted for each pheromone application and each phenological stage of the crop using the plots as replications. The orientation disruption percentage of the males was calculated independently from the difference between trap captures in pheromone treated and control plots in each block (from the detransformed data).

\section{Results}

\section{Moth monitoring}

The T. absoluta trap catches in the control plots showed a high moth population at the tomato vegetative stage (mean $233.3 \pm 53.1 \mathrm{males} /$ trap/day) compared with the reproductive stage (mean 68.3 \pm 19.3 males/trap/day) (Figure 1).

In the morning before the first synthetic sex pheromone application, moth catch was high (a mean of $314.9 \pm 51.7$ males/trap), while the second pheromone application (nine weeks after transplanting) was made with a lower pest population and a mean of $80.5 \pm 29.6$ males/trap was captured.

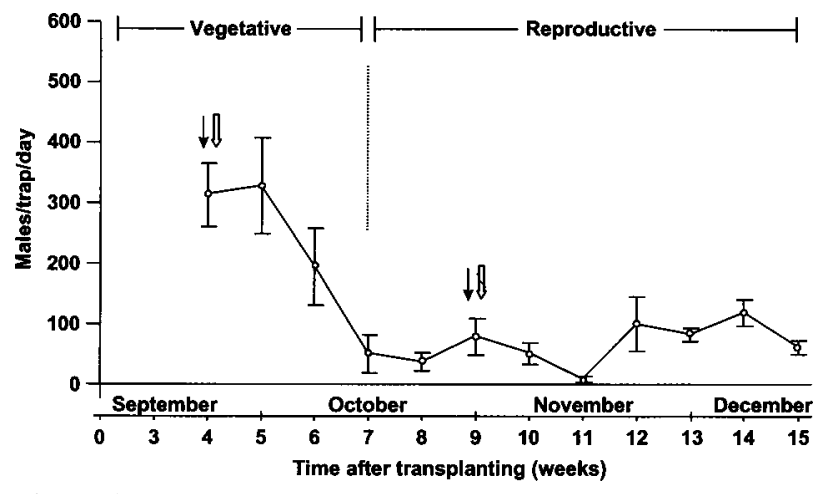

Figure 1. T. absoluta males caught in the pheromone-baited traps during the phenological stages of the fresh-market tomato, in the untreated control plots (D1 treatment). Turvolândia, Brazil, 1996. Mean catch per trap per day from data from three round traps; bars = standard errors. Symbols above the tendency lines indicate $\Longrightarrow$ pheromone application and $\longrightarrow$ intensive insecticide application (see text). 


\section{Orientation disruption to pheromone-baited traps}

Male catches in traps were affected by the synthetic sex pheromone dose $\left(\mathrm{X}_{1}\right)$ applied in the plot and by the time after application $\left(\mathrm{X}_{2}\right)$ at the vegetative $(\mathrm{F}=44.31$, df $\left.=4,19, \mathrm{p}<0.01, \mathrm{R}^{2}=0.90\right)$ and reproductive stages $\left(\mathrm{F}=6.03, \mathrm{df}=4,25, \mathrm{p}<0.01, \mathrm{R}^{2}=0.49\right)$ in staked tomato plants. There was no significant interaction $(\mathrm{p}>0.05)$ between the pheromone dose and the time after its application at either tomato phenological stage.

Two surface response plots were obtained from the selection of multiple regression models adjusted to reduction of male catches by each pheromone application (Figures 2 and 3). At the vegetative stage of the tomato plant, male capture tended to be reduced with the increase in the pheromone dose up to approximately $35 \mathrm{~g}$ a.i./ha (Figure 2). An average $90 \%$ communication disruption was found with this dose, based on the comparisons with trap catches in control plots ( $0 \mathrm{~g}$ a.i./ha) at 28 days after pheromone application. On this occasion, the adult T. absoluta population reached the lowest level $(<70$ males/trap/day) at the vegetative stage (Figure 1).

At the tomato plant reproductive stage there tended to be a reduction in the number of males captured with the increase in the pheromone dose up to $50 \mathrm{~g}$ a.i./ha (Figure 3). Approximately $60.4 \%$ sexual communication was found for this same dose close to 16 days after the second pheromone application, when fewer than 15 males/trap were caught in control plots. On the other hand, the efficiency of the pheromone treatments was reduced when

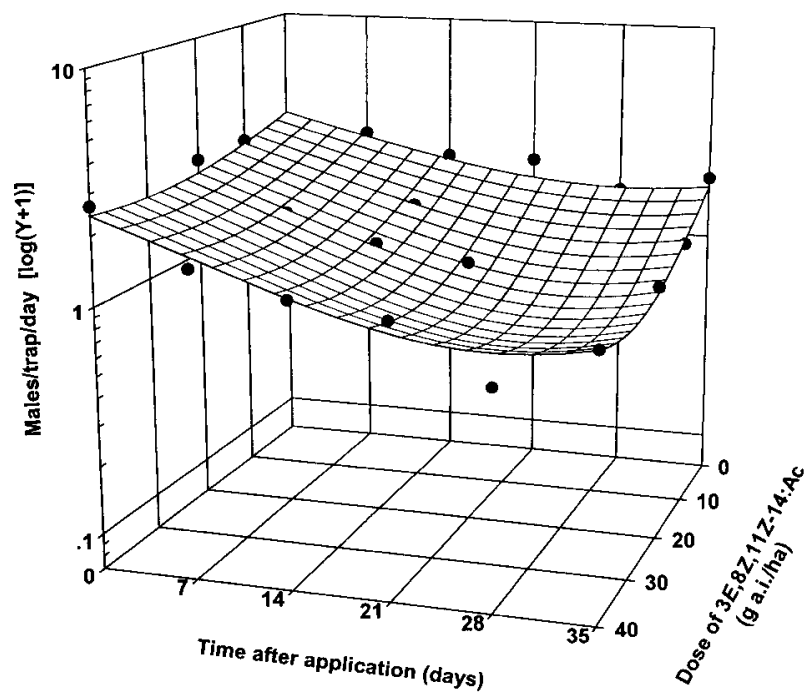

Figure 2. Effect of synthetic sex pheromone dose $\left(X_{1}\right)$ and time after pheromone application $\left(\mathrm{X}_{2}\right)$ on capture of $T$. absoluta males in pheromone baited-traps, during the vegetative stage of the freshmarket tomato. Model: $\log _{10}($ male catches+1) $=3.1829$ 0.0605. $\left(\mathrm{X}_{1}\right)+0.001 .\left(\mathrm{X}_{1}\right)^{2}-0.1111 .\left(\mathrm{X}_{2}\right)+0.002 .\left(\mathrm{X}_{2}\right)^{2} ; \mathrm{R}^{2}=0.90$, $\mathrm{F}=44.31, \mathrm{df}=[4,19], \mathrm{p}<0.01$.

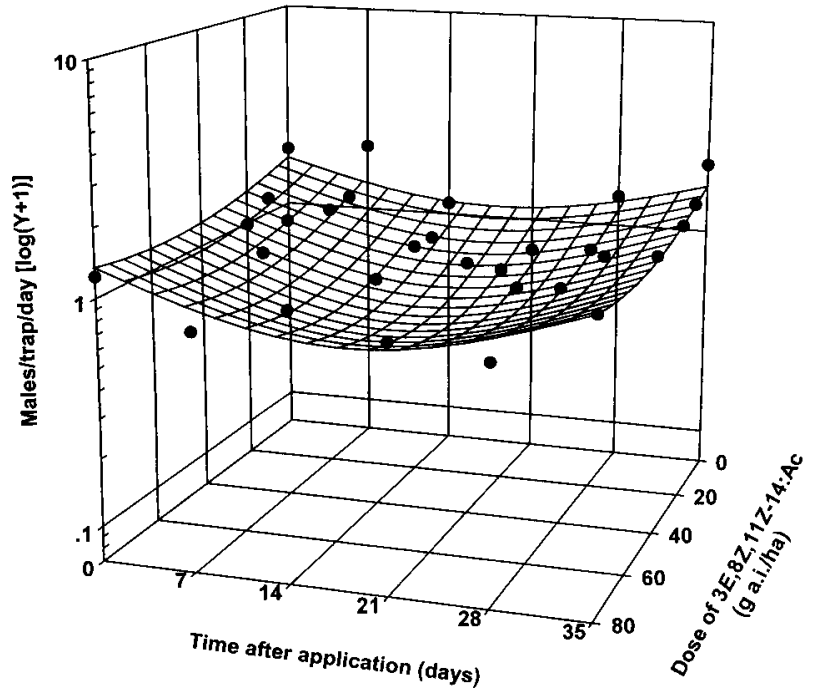

Figure 3. Effect of synthetic sex pheromone dose $\left(X_{1}\right)$ and time after pheromone application $\left(\mathrm{X}_{2}\right)$ on capture of $T$. absoluta males in pheromone baited-traps, during the reproductive stage of the fresh-market tomato. Model: $\log _{10}($ male catches +1$)=1,7197-$ 0.017. $\left(\mathrm{X}_{1}\right)+0.002 .\left(\mathrm{X}_{1}\right)^{2}-0.0654 .\left(\mathrm{X}_{2}\right)+0.0018 .\left(\mathrm{X}_{2}\right)^{2} ; \mathrm{R}^{2}=0.49$, $\mathrm{F}=43.03$, df $=[4,25], \mathrm{p}<0.01$.

the adult population increased 21 days after the second application (13 weeks after transplanting).

\section{Mating disruption in cages}

The percentage of cages with mating was not affected by the synthetic sex pheromone dose applied in the plot. In all the plots involved and on both the assessment dates, the spermatozoid bundles were found at least one female per cage.

\section{Foliage and fruit damage}

The percentage of mined leaflets was not affected by the dose of synthetic sex pheromone applied, either at the tomato plant vegetative stage $(\mathrm{t}=0.43, \mathrm{n}=17, \mathrm{p}=0.67$, partial $\mathrm{r}=0.09)$ or at the reproductive stage $(\mathrm{t}=0.46$, $\mathrm{n}=22, \mathrm{p}=0.65$, partial $\mathrm{r}=0.04$ ).

The mean percentage of mined leaflets varied from 3.5 to $10.5 \%$ at the vegetative stage of the tomato plant (Figure 4). During the tomato fruit production, the leaf attack intensity increased from $5.1 \%$ mined leaflets on the day of the second pheromone application to $45.0 \%$ at the last assessment (Figure 5).

Fruit damage by $T$. absoluta was also not significantly affected by the synthetic sex pheromone doses $(\mathrm{t}=0.07$, $\mathrm{n}=17, \mathrm{p}=0.94$, partial $\mathrm{r}=0.02$ ). At the first assessment (nine weeks after transplanting), the $T$. absoluta attack was more intense, with $32.4 \%$ damaged fruit; however, in the other assessments was found $8 \%$ to $14 \%$ of damaged fruits (Figure 6). 


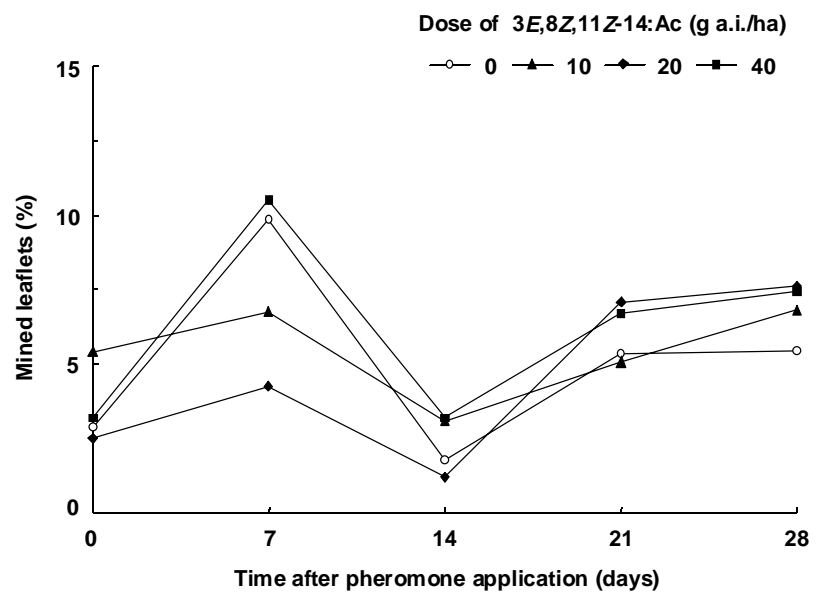

Figure 4. Percentage of mined leaflets by $T$. absoluta larvae related to the doses of $3 E, 8 Z, 11 Z-14$ :Ac and time after pheromone application, during the vegetative stage of the fresh-market tomato. There was no significant effect of the doses of synthetic sex pheromone doses on foliage damage $(n=17, p=0.67$, partial $r=0.09)$.

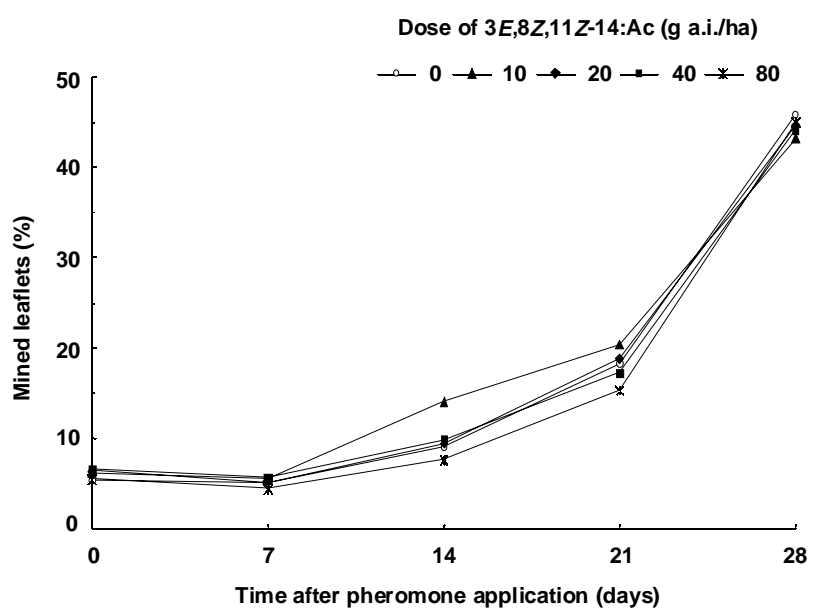

Figure 5. Percentage of mined leaflets by $T$. absoluta larvae related to the doses of $3 E, 8 Z, 11 Z-14$ :Ac and time after pheromone application, during the reproductive stage of the fresh-market tomato. There was no significant effect of the doses of synthetic sex pheromone doses on foliage damage $(\mathrm{n}=22, \mathrm{p}=0.65$, partial $\mathrm{r}=0.04)$.

\section{Discussion}

The ability of T. absoluta males to localize pheromonebaited traps was reduced in the pheromone-treated plots. When the dose of $3 E, 8 Z, 11 Z-14$ :Ac increased, the level of interruption in the trap catches at both phenological stages of the crop increased. Low doses of synthetic sex pheromone, between 10 to $40 \mathrm{~g}$ a.i./ha, caused high level (70-80\%) interruption in pheromonal communication. On the other hand, high doses of pheromone ( $80 \mathrm{~g}$ a.i./ha) did not reduce male catches proportionally.

The fall in orientation disruption observed with the increase in the field male population showed that the efficiency of the pheromone treatment may depend on the

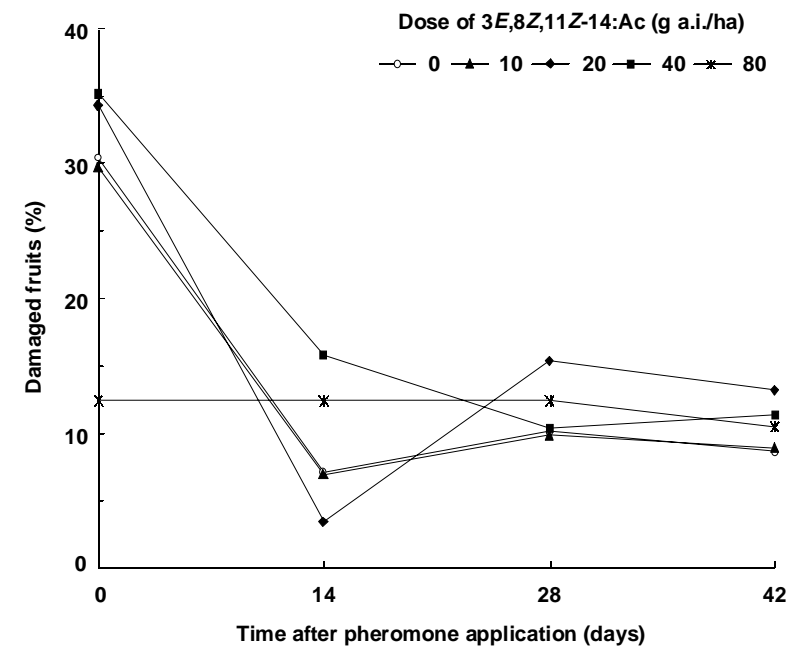

Figure 6. Percentage of damaged fruits by $T$. absoluta larvae related to the doses of $3 E, 8 Z, 11 Z-14$ :Ac and time after pheromone application, during the reproductive stage of the fresh-market tomato. There was no significant effect of the doses of synthetic sex pheromone doses on foliage damage $(n=17, p=0.94$, partial $r=0.02)$.

adult density. High population densities may favor mating by the increase in competition among calling females and synthetic pheromone dispensers, by reducing the distance among adults, increasing the likelihood of casual mating and consequently, less time spent searching for females ${ }^{19}$. As we worked with a fixed number of traps simulating calling females, with a high male population, the chances of localizing females or traps would be greater. This explanation was supported by the results of Palaniswamy et al. ${ }^{20}$, who found low efficiency at high doses for mating disruption of the Alsophila pometaria (Harris) in the presence of high male/female ratios in elm trees. Suckling et al. ${ }^{21}$ also reported that in Epiphyas postivittana (Walker) there was an increase in the incidence of mated females inside the pheromone treated areas with the increase in the number of males in the apple orchard.

Although male trap catches were significantly affected by the $T$. absoluta synthetic sex pheromone dose in the plots, no other assessment method showed the same tendency. Even with a higher pheromone dose compared to that existing in the female sex glands $(<5 \mathrm{ng}$ of $3 E, 8 Z, 11 Z-14: A c)^{11}$, it was not possible to prevent mating in the cages or reduce leaf and fruit damage in the pheromone-treated plots.

It is unlikely that a reduction in male catches is linked to an equivalent mating reduction. For many moths, it is especially difficult to obtain a relationship between male catches and plant damage because many factors may influence differentially the trap catches, population dynamics, adult movements and their distribution ${ }^{22}$. On the other hand, mating tables are also limited and require 
caution in interpreting data obtained ${ }^{21}$. In this study, the tethered males were submitted to mating for only one day in the pheromone permeated atmosphere. This exposure time of the males to the pheromone may be insufficient for the expected neurophysiological disturbances to occur ${ }^{23}$ which result in mating disruption.

Patterns of leaf and fruit damage provide an economically relevant method to assess the pheromone disruption as a pest control tactic. All the pheromone treatments had intense foliage and fruit attacks by $T$. absoluta larvae and did not differ statistically from the result in the control plots. High caterpillar density during the tomato fruit production, in both plots, caused damage to fruits well above the economically acceptable limit (1$5 \%$ damaged fruits) proposed for fresh-market and processing tomatoes ${ }^{18}$. This is due to the limited efficiency of insecticides in controlling high pest infestation when caterpillars are protected inside branches and fruits ${ }^{6}$.

There are several possible reasons for the failure of $T$. absoluta mating disruption. First, the mating success of the species in areas treated with pheromone could be associated with an inappropriate composition of the synthetic sex pheromone. The synthetic molecule of the major component $(3 E, 8 Z, 11 Z-14: A c)$ of the T. absoluta sex pheromone has performed well for field trapping of males compared to virgin females as bait ${ }^{11}$; however, the minor component $3 E, 8 Z-14$ :Ac found in the sex gland of calling females ${ }^{12,13}$ may be advantageous for the mating success of the species when the males are looking for partners within areas with a dense cloud of high concentration of $3 E, 8 Z, 11 Z-14$ :Ac. Synthetic components in sex pheromones used in isolation may cause both a reduction in the search effort and male orientation disruption because of its concentration. However, the level of mating disruption due to competitive attraction created by the synthetic pheromone depends on the presence of all the components in precise proportions and concentrations close to the natural pheromone emitted by the female to maximize the competition among the dispensers and females in calling behavior $^{24}$. These findings could explain the differences observed among the results of pheromone-baited traps and mating tables, as well as the limited efficiency of high sex pheromone doses to prevent complete trap localization by the males.

On the other hand, successful mating disruption with a single component sex pheromone such as that of Lymantria dispar $L$. in forests in the United States and Canada 25 suggest that we cannot discard the future possibility of controlling $T$. absoluta populations with the sex pheromone component, 3E,8Z,11Z-14:Ac.
The females could mate because of the inappropriate pheromone emission rate and/or the low pheromone concentration in the atmosphere when the moths mate. Pheromone evaporation from the rubber septa dispenser follows a first-order process, that is, there is a high release rate at the beginning which gradually falls proportionally with the concentration of the chemical in the dispenser ${ }^{26}$. Along with this fact, the success of the matings among T. absoluta adults kept in cages suggests that the majority of $3 E, 8 Z, 11 Z-14$ :Ac impregnated in the rubber septa has been lost in less than seven days after fixing the dispenser in the field, because of high release rates of the chemical in the first days. This premature release of the pheromone could be attributed to high daily temperatures (23.0 \pm $5.0^{\circ} \mathrm{C}$ ) and high wind speeds which occur during almost all the tomato plant development.

Another very important factor was the moment of pheromone application. The first pheromone application was delayed until 30 days after transplanting because of operational problems, when coincidentally $T$. absoluta had already become established in the crop and had the highest infestation level, both of moths (Figure 1) and caterpillars on the foliage (Figure 4). The appearance of the first $T$. absoluta adults in tomato crops would be the best moment to apply the sex pheromone. High pest population densities have also been the cause of low efficiency in mating disruption in other gelechiids such as K. lycopersicella ${ }^{7}$ and A. lineatella ${ }^{9}$.

Failure in pheromone disruption in other moth pests has also been attributed to mated female migration to within the areas treated with pheromone, where their oviposition results in plant damage and distorts the results ${ }^{19}$. We believe that the migration of mated females from nontreated areas to the pheromone-treated plots could have occurred in our experiments.

\section{Conclusions}

The results indicate that we need to carry out more detailed ecological and pheromone studies for better understanding of male orientation and to achieve a more effective mating disruption in this pest. With these advances, we expect that the $T$. absoluta synthetic sex pheromone will be used for mating disruption with desirable control levels in the IPM tomato plant programs in Brazil.

\section{Acknowledgements}

We would like to thank Dr. Angenor Mafra-Neto, University of California, Riverside, for supplying the dispensers (rubber septa). We also thank by Dr. Marcelo 
Coutinho Picanço, Dr. Terezinha M.C. Della Lucia (Departamento de Biologia Animal, Universidade Federal de Viçosa, Viçosa, MG, Brazil), and Dr. Paulo Henrique G. Zarbin (Departamento de Química, Universidade Federal do Paraná, Curitiba, PR, Brazil) for their valuable suggestions during the preparation of the manuscript. This research was supported by the US-Latin America Cooperative Science Program (Brazil) (NSF \# INT9202380), the Conselho Nacional de Desenvolvimento Científico e Tecnológico (CNPq, Brazil) and in part by the Czech Grant Agency (A.S., Grant 203/93/0102).

\section{References}

1. Moore, J. E. Tropical Pest Management 1983, 29, 231.

2. Souza, J. C. de; Reis, P. R.; Salgado, L. O. Traça-dotomateiro: histórico, reconhecimento, biologia, prejuízos e controle. Boletim Técnico № 38, EPAMIG, Belo Horizonte, Brazil, 1992.

3. Haji, F. N. P.; Freire, L. C. L.; Roa, F. G.; Silva, C. N.; Sousa Júnior, M. M.; Silva, M. I. V. An. Soc. Entomol. Brasil 1995, 24, 587.

4. Picanço, M.; Guedes, R. N. ; Leite, G. L. D.; Fontes, P. C. R.; Silva, E. A. Hortic. bras. 1995, 13, 180.

5. Imenes, S. D. L.; Campos, T. B.; Takematsu, A. P.; Bergmann, E. C.; Silva M. A. D. Arq. Inst. Biol., S. Paulo 1992, 59, 1.

6. França, F. H. Hortic. bras. 1993, 11, 176.

7. Jenkins, J. W.; Doane, D. J.; Schuster; D. J., McLaughlin, J. R.; Jiménez, M. J. in Behaviourmodifying chemical for insect management; Ridgway, R. M.; Silverstein, R. M.; Inscoe, M.N., Ed.; Marcel Dekker; New York, 1990, p 270.

8. Staten, R. R.; El-Lissy, O.; Antilla, L. in Insect pheromone research: new directions; Cardé, R.T.;Minks, A. K. Ed.; Chapman \& Hall; New York, 1997, p 383.

9. Molinari, F.; Cravedi, P. Bollettino di Zoologia Agraria e di Bachicoltura 1989, 21, 163.

10. Attygalle, A. B.; Jham, G. N.; Svatos, A.; Frighetto, R.
J. S.; Meinwald, J.; Vilela, E. F.; Ferrara, F. A.; UchoaFernandes, M. A. Tetrahedron Lett. 1995, 36, 5471.

11. Attygalle, A. B.; Jham, G. N.; Svatos , A.; Frighetto, R. J. S.; Meinwald, J.; Vilela, E. F.; Ferrara, F. A.; UchoaFernandes, M. A. Bioorg. Med. Chem. 1996, 4, 305.

12. Griepink, F.C.; van Beek, T.A.; Posthumus, M.A.; Groot,A.; Visser, J. H.; Voerman, S. Tetrahedron Lett. 1996, 37, 411.

13. Svatos, A.; Attygalle, A. B.; Jham, G. N.; Frighetto R. T. S.; Vilela, E. F.; Šaman, D.; Meinwalad, J. J. Chem. Ecol. 1996, 22, 787.

14. Michereff Filho, M.; Vilela, E. F.; Attygalle, A. B.; Meinwalad, J.; Svatos, A.; Jham, G. N. J. Chem. Ecol. 2000, 26, 875.

15. Minks, A. K.; Cardé, R. T. Entomol. Exp. Appl. 1988, 49, 25.

16. Andrei, E. Compêndio de defensivos agrícolas, 5th Ed. Organização Andrei; São Paulo, Brazil, 1996.

17. Uchoa-Fernandes, M. A.; Vilela, E. F.; Della Lucia, T. M. C. Rev. Brasil. Biol. 1995, 5, 67.

18. Gravena, S. In Anais of the $2^{\circ}$ Encontro Nacional de Produção e Abastecimento de Tomate; Castellani, P. D.; Braz, L. T.; Shurato-Musca, M. G. C., Ed.; Unesp, Jaboticabal, Brazil, 1991, vol. 2, p 105.

19. Cardé, R. T.; Minks, A.K.Annu. Rev. Entomol. 1995, 40, 559.

20. Palaniswamy, P.; Underhill, E. W; Gillott, C.; Wong, J. W. Environ. Entomol. 1986, 15, 943.

21. Suckling, D. M.; Karg, G.; Bradley, S. J.; Howard, C. R. J. Econ. Entomol. 1994, 87, 1477.

22. McNeil, J. N. Annu. Rev. Entomol. 1991, 36, 407.

23. Sanders, C. J. in Insect pheromone research: new directions; Cardé, R. T.; Minks, A. K., Ed.; Chapman \& Hall; New York, 1997, p 333.

24. Palaniswamy, P.; Underhill, E. W. Environ. Entomol. 1988, 17, 432.

25. Leonhardt, B.A.; Mastro, V. C.; Leonard, D. S.; McLane, W.; Reardon, R. C.; Thorpe, K. W. J. Chem. Ecol. 1996, 22, 1255.

26. McDonough, L. M.; Brown, D. F.; Aller, W. C. J. Chem. Ecol. 1989, 15, 779. 